\title{
Early Adolescents' Emotional and Behavioral Difficulties, Student-Teacher Relationships, and Motivation to Defend in Bullying Incidents
}

\author{
Nathalie Ophelia lotti ${ }^{1} \cdot$ Robert Thornberg $^{2} \cdot$ Claudio Longobardi $^{3} \cdot$ Tomas Jungert $^{1}$ (D
}

Published online: 20 August 2019

(C) The Author(s) 2019

\begin{abstract}
Background School bullying is a widespread phenomenon across the world, which involves bystanders who take on various roles. Motivation to defend victims is important to investigate because it helps us devise better, evidence-based, anti-bullying interventions.

Objective We aimed to determine whether students' behavioral and emotional strengths and difficulties and student-teacher relationships were associated with different types of motivation to defend victims of bullying. The hypotheses were (1) emotional and behavioral difficulties will be associated with less autonomous and introjected motivation to defend and greater extrinsic motivation to defend and (2) close student-teacher relationships will be associated with greater autonomous motivation to defend, and less extrinsic motivation to defend.

Method Data were collected from 483 Swedish early adolescents who completed a survey in their classrooms.

Results Results showed that, among boys and girls, close student-teacher relationships were positively associated with autonomous motivation and negatively associated with extrinsic motivation to defend, while negative expectations concerning teachers were associated with all forms of motivation to defend. Emotional and behavioral difficulties were only associated with introjected motivation to defend among girls. Furthermore, extrinsic motivation to defend was associated with the interactions between individual differences in behavioral and emotional difficulties and negative expectations.

Conclusions Adolescents who are more occupied with wanting to have a better relationship with their teachers might be motivated to be involved in good social relationships with others. The results also indicate that closeness in student-teacher relationships is important for greater autonomous motivation to defend victims during bullying.
\end{abstract}

Keywords Bullying $\cdot$ Bystander $\cdot$ Defending $\cdot$ Student-teacher relationships $\cdot$ Selfdetermination theory $\cdot$ Motivation to defend

Tomas Jungert

tomas.jungert@psy.lu.se

1 Lund University, Box 213, 22100 Lund, Sweden

2 Linköping University, IBL, 58183 Linköping, Sweden

3 University of Turin, Via Verdi 10, 10124 Turin, Italy 


\section{Introduction}

School bullying is a widespread phenomenon across the world (Chester et al. 2015). It involves not only bullies and victims, but also bystanders, who can take various roles, including assisting the bullies, laughing and cheering on the bullying, remaining passive, and defending the victim (Salmivalli 2010). Previous studies have shown that a lower prevalence of pro-bullying behaviors and a greater prevalence of defending behaviors are associated with less bullying among classmates (Kärnä et al. 2011; Nocentini et al. 2013; Salmivalli et al. 2011). The mechanisms of defending victims in school bullying, such as motivation to defend, are therefore in need of more research, in order to add to the bullying literature as well as to develop better policies and intervention programs that can tackle bullying effectively and help decrease peer victimization (Espelage et al. 2012).

\section{Self-determination Theory and Motivation to Defend a Victim in Bullying}

According to self-determination theory (SDT; Deci and Ryan 2000), a distinction can be made between autonomous and controlled motivation. The former involves acting with a sense of choice and having a number of options available, while the latter involves acting with a sense of pressure or of being required to involve oneself in activities that one might not otherwise pursue. SDT assumes that autonomous and controlled motivations differ in terms of both their fundamental regulatory processes and their accompanying experiences. Furthermore, SDT often describes autonomous motivation as the combination of identified and integrated regulation. Identified regulation refers to when people are driven by the recognition and acceptance of the underlying value of a behavior, while integrated regulation refers to when people are driven by their identification of that behavior with other aspects of the self (one example of this is when a person says, "I help people because helping is part of who I am"). Controlled motivation, by contrast, is the combination of external and introjected regulation. The former refers to when behavior is controlled by external contingencies in terms of attaining rewards or avoiding being punished, and the latter involves the person's ego and the emergence of feelings of pride, guilt, or shame when engaging in a particular behavior (Ryan and Deci 2017). However, it is important to distinguish between introjected and external motivation, as introjected motivation is associated with internal pressure and tension, and it is a type of internalization that phenomenally has a more internal perceived locus of causality than external regulation, which is phenomenally controlled by external entities or persons (Ryan and Deci 2017).

Defending others is an example of prosocial behavior, which has been found to be associated with autonomous motivation (Hardy et al. 2015). Specifically, autonomous helpers gave more assistance and were perceived as more helpful than controlled helpers in situations related to doing something for a good cause and when they were asked to donate money to another study participant (Weinstein and Ryan 2010). In school bullying literature, Jungert et al. (2016) found that autonomous motivation to defend a victim was positively associated with defending and negatively associated with passive bystanding, whereas extrinsic motivation to defend was positively associated with pro-bullying behaviors (i.e., assisting the bullies or reinforcing the bullying). Nevertheless, there is limited research on middle school students' autonomous, introjected and extrinsic motivation to defend victims. Therefore, we need to know more about how various factors might be 
associated with or explain the variability in autonomous motivation to defend victims as well as other forms of motivation among students in schools, which is the goal of the current study.

\section{Student-Teacher Relationship Quality and Motivation to Defend}

According to SDT, satisfaction of the three basic needs-autonomy, competence, and relatedness-is required for autonomous motivation to engage (Deci and Ryan 2000). The need for autonomy is defined as the need to be able to behave in line with one's own preferences, make one's own choices, and autonomously express one's feelings in contrast to more pressured or alienated functioning. The need for competence refers to a sense of being efficient, receiving positive feedback, and having opportunities to develop new skills. The need for relatedness refers to a need for social belonging, including warm and caring relationships and positive alliances with others (Baumeister and Leary 1995; Deci and Ryan 2000). Close interactions with peers and teachers will therefore attend to this need. Warm and supportive student-teacher relationships have previously been associated with defending bully victims (Jungert et al. 2016; Thornberg et al. 2017), and autonomous motivation to defend victims of bullying (Jungert et al. 2016).

However, in middle school, young adolescents experience swift cognitive, emotional, physical, and social development, which has been confirmed by longitudinal studies (Meeus 2016). Concurrently, students must adjust to their new school environment. These developmental changes can result in both social and behavioral difficulties such as decreases in school satisfaction, reactions to teachers, youth self-esteem, and prosocial behavior (Waters et al. 2009). Students might also see substantial changes in their social networks (Ryan and Patrick 2001) as the importance of relations with peers grows and the pressure to "fit in" strengthens (Hardy et al. 2015). These changes might have such an effect on students that they encounter complications in interpersonal as well as student-teacher relationships.

\section{Emotional and Behavioral Difficulties and Motivation to Defend}

Few studies have investigated emotional and behavioral difficulties among bystanders of school bullying, or how these relate to their motivation to intervene in bullying. Regarding students with behavioral difficulties such as attention-deficit hyperactivity disorder (ADHD) and general conduct problems, researchers have generally assumed that these students might not have sufficient understanding of how to engage in prosocial behavior due to their cognitive deficits (Andrade and Tannock 2014). Several studies have found that inattentive and hyperactive/impulsive early adolescents default to non-prosocial conduct to gain social impact (Bloomquist et al. 1997; Hoza 2007). Thus, when students with behavioral difficulties interact in certain situations, such as bullying incidents, their interactions are problematic and might lead to continued peer difficulties (Hoza 2007).

Regardless of the studies above, we do not know whether emotional and behavioral difficulties are associated with various forms of motivation to defend victims of bullying; more research is needed to clarify whether that is the case. When it comes to early adolescents with peer relationship problems, Wentzel (2017) found that they had weaker beliefs in the self and put less value in prosocial forms of behavior compared to children without problematic peer relationships (Wentzel 2017). Thus, it seems plausible to hypothesize that students with peer relationship problems would be less autonomously and introjectedly motivated to defend victims in bullying situations, whereas students with few emotional 
and behavioral problems would be more autonomously and introjectedly motivated to defend victims.

\section{Interaction Between Student-Teacher Relationship Quality and Difficulties}

In addition, student-teacher relationships have been associated with children's and early adolescents' emotional and behavioral strengths and difficulties. Student-teacher closeness has mostly shown associations with positive adjustment outcomes as it probably creates basic need nurturing environments that facilitate the development of intrinsic goals and autonomous motivation (Kasser et al. 1995). Lack of closeness between students and teachers will probably result in need thwarting, which leads to extrinsic aspirations and motivation (Kasser et al. 1995). Thus, we hypothesize that closeness will positively be associated with autonomous motivation to defend and negatively associated with extrinsic motivation to defend.

Koomen and Jellesma (2015) suggest another dimension of student-teacher relationships termed negative expectations, which they define as a desire for more positive attention (e.g., students wish that their teacher would listen to them more, could spend more time with them, knew them better, and that they could talk about more things with their teacher). In their study, Koomen and Jellesma (2015) found that negative expectations were related to more emotional problems and hyperactivity/attention problems, and less prosocial behavior. On the other hand, Longobardi et al. (2016) did not find negative expectations to be significantly associated with prosocial behavior or any problems/difficulties measured by the Strengths and Difficulties Questionnaire (SDQ; Goodman 1997). A possible explanation to the mixed findings might be due to age and cultural differences between the samples. Koomen and Jellesma (2015) examined Dutch elementary school students, whereas Longobardi et al. (2016) investigated Italian middle school students. Nevertheless, the dimension of negative expectations in student-teacher relationships is a novel and still overlooked construct in the literature, and further research is needed, such as whether negative expectations might be associated with various motivations to defend bullying victims. It also remains uncertain whether student-teacher relationship quality interacts with students' emotional and behavioral problems to influence their motivation to defend victims of bullying.

\section{Gender Differences}

Finally, previous studies have found that girls are more inclined than boys to defend victims in bullying (Batanova et al. 2014; Oh and Hazler 2009; Trach et al. 2010). A recent study found that emotional difficulties were associated with greater defending for girls, while social skills were associated with greater defending for boys and girls (Jenkins et al. 2017). In addition to the direct positive relation to defending among girls, emotional difficulties were indirectly and negatively related to defending via poor social skills among boys and girls. Furthermore, research on gender differences suggests that boys tend to have more behavioral difficulties than girls (Barkley 2014; Gaub and Carlson 1997), while girls appear to exhibit more emotional symptoms than boys (Crick et al. 2002; Hampel and Petermann 2006; Hankin et al. 2007; Prinstein et al. 2005). To summarize, the findings on gender differences in emotional and behavioral difficulties are mixed and important to investigate, but we cannot offer hypotheses for this study. Still, it motivates us to examine 
separately for boys and girls whether emotional and behavioral difficulties are linked to motivation to defend victims.

\section{The Current Study}

Based on previous findings, our goal was to examine differences in early adolescents' emotional and behavioral difficulties, student-teacher relationships, and self-determined motivation to defend victims during incidents of peer victimization between boys and girls. Because a large body of research has examined the disadvantages of conflictual or negative student-teacher relationships (McGrath and Van Bergen 2015), including its positive association with pro-bullying behavior (Jungert et al. 2016), we focused on contrasting positive and warm student-teacher relationships with negative expectations instead. Furthermore, we aimed to examine associations of early adolescents' motivation to defend with their difficulties and the quality of their student-teacher relationships. Our hypotheses are the following:

Hypothesis 1 Emotional and behavioral difficulties will be associated with less autonomous and introjected motivation to defend and greater extrinsic motivation to defend.

Hypothesis 2 Close student-teacher relationships will be associated with greater autonomous motivation to defend, and less extrinsic motivation to defend.

In addition to the hypotheses above, associations between age and difficulties and prosocial motivation were examined, as well as interaction effects in a more exploratory fashion because they had not been studied previously.

\section{Method}

\section{Participants and Procedure}

Participants were recruited from 40 classes in grades 5-8 in thirteen elementary schools in Sweden. The Swedish school system begins with preschool class when children turn six, followed by 9 years of compulsory schooling, including primary school (grades 1-6) and secondary school (grades 7-9). In both primary and secondary school, students have one classroom (homeroom) and a classroom teacher. The main difference is that in primary school, most of the lessons take place in one classroom across most school subjects with the classroom teacher, while in secondary school, the lessons take place in several classrooms with several subject-specific teachers, even if the classroom teacher usually teaches each day and in more than one subject.

A non-probability, two-step sampling procedure was used in this study. First, a purposive sampling of schools was carried out, which resulted in the inclusion of 13 schools, including two schools in the countryside, one school in a small town, nine schools in different neighborhoods of two medium-sized Swedish cities, and one school in a large Swedish city. Second, convenience sampling was conducted in each school with the cooperation of class teachers. Parental consent letters were distributed to the families of all 783 children in these classes. The respondents did not receive any payment or other forms of reimbursement for their participation. Overall, 506 students completed the survey (participation 
rate $=65 \%$ ). 304 were female, 193 were male, 9 did not indicate a gender. In addition, 23 students were not in the age range of 11-14 years.

Seven multivariate outliers (i.e., cases with Mahalanobis distances exceeding the critical value) were removed prior to all analyses. Furthermore, the nine students who did not provide information on their gender and the 23 students who were not aged 11-14 were eliminated from the data set. To manage the remaining missing data, multiple imputation analysis was performed in EQS (Bentler 1995). This was done by applying expectation maximization (EM). The EM technique is recommended when the data are missing not at random (MNAR) or when it is not possible to know if the data are missing at random (MAR) (Myers 2011; Roth et al. 1999). Thus, the final sample for the current study included 467 participants (283 females, 184 males), whose age varied from 11 to 14 years $(M=11.69 ; S D=.96$ years). They represented all classes from the original sample, which had the following grade distribution: $18 \%$ fifth graders, $29 \%$ sixth graders, $28 \%$ seventh graders, $25 \%$ eighth graders.

The students filled out the questionnaire in their ordinary classroom settings during regular classroom hours. The students were informed that participation was voluntary and that they had the right to drop out of the study if they desired, and were given opportunities to ask questions. Students were requested to answer all the questions truthfully. Students who had not been given consent from their parents, or did not want to participate, received a different task from their teachers, such as reading a book. In five of the 13 schools ( 20 classes, $N=225$ ) that were able to provide computers or tablets, the survey was answered digitally via Sunet Survey. At the remaining schools, the questionnaire was completed analogously in a pen and paper format. Completion of the questionnaire took between 20 and $40 \mathrm{~min}$, and at least one author was available to answer students' questions during this time.

The two-step sampling procedure led to a sample of adolescents from various socioeconomic (i.e., lower- to upper-middle class) and socio-geographic backgrounds.

\section{Materials}

\section{Student Perception of Affective Relationship with Teacher Scale (SPARTS)}

This self-report scale by Koomen and Jellesma (2015) designed for children/early adolescents aged 9-14 years was used to measure participants' perception of their relationship with their main teacher. The scale comprised 14 items, measuring the two dimensions of affective student-teacher relationship quality: (a) closeness (e.g., "I feel relaxed with my teacher") and (b) negative expectations (e.g., "I feel sad if my teacher tells me that I do something wrong"). Each item was answered on a 5-point Likert scale (1="no, that is not true", $5=$ "yes, that is true").

The construct validity of this scale has been supported by exploratory and confirmatory factor analyses (Koomen and Jellesma 2015). Furthermore, a confirmatory factor analysis (CFA) was conducted to verify that the scale was two-dimensional. The initial model fit indices were poor. The assessment of the modification indices revealed that items 1, 2, and 4 of the closeness subscale had very low loadings on that factor and were thus removed from further analyses. In addition, covariance paths between items 1, 2, 5, 6, and 7 of the negative expectations subscale significantly increased the fit. The final model fit indices were good. In the current study, the internal consistency reliabilities for the two factors were .81 and .63 for the closeness and negative expectations subscales, respectively, for 
boys, and .80 and .66 for girls. The values were acceptable as all Cronbach's alpha values above .60 can be assumed to be acceptable (Aron et al. 2013).

\section{Motivation to Defend Scale (MDS)}

The Motivation to Defend Scale (Jungert et al. 2016), which comprises 14 items based on SDT (Deci and Ryan 2000), was used to assess early adolescents' motivation to defend victims during bullying episodes. The items measure four motivational aspects in four subscales: extrinsic, introjected, identified, and intrinsic motivation. The latter three of these motivational aspects are measured by three items each, while extrinsic motivation is measured using five items. Participants were asked to think of situations where they had witnessed another student being bullied and to report why they would help a victim. Example items include "Because I like to help other people" (intrinsic motivation), "Because I think it is important to help people who are treated badly" (identified regulation), "Because I would feel like a bad person if I did not try to help" (introjected regulation), and "To become popular" (extrinsic motivation). In the first part of the questionnaire, participants answer each item on a 5-point scale ranging from 1 ("completely disagree") to 5 ("completely agree"). In the current study, the internal consistency reliabilities were $.78, .63$, and .76 for the autonomous motivation, introjected motivation, and extrinsic motivation subscales, respectively, for boys, and .72, .62, and .66 for girls.

\section{Strengths and Difficulties Questionnaire (SDQ)}

The SDQ (Goodman 1997) is a brief behavioral screening questionnaire used to generate a profile of child and adolescent behaviors, emotions, and relationships (Goodman et al. 1998). It defines difficulties as hyperactivity/inattention, conduct problems, emotional symptoms, and peer relationship problems, whereas strengths are defined as prosocial behavior. The SDQ has been used to measure the behavioral profiles of both bullies and victims (e.g. Gini 2008). It consists of 25 items, divided into 5 subscales: (a) emotional symptoms; (b) conduct problems; (c) hyperactivity/inattention; (d) peer relationship problems; and (e) prosocial behavior. Each item is answered on a 3-point Likert scale $(1=$ not true, $3=$ certainly true). In the current study, the Swedish adaptation of the SDQ selfreport version designed for adolescents aged 11-17 years was used (Malmberg et al. 2003). We used the scores reflecting difficulties (i.e., based on the scores on emotional symptoms, conduct problems, hyperactivity/inattention, and peer relationship problems), which may be summed up to create a total difficulties score.

In the current study, the internal consistency for total difficulties was .91 for both boys and girls.

\section{Ethics}

The study was ethically approved by the Department of Psychology at the university. Parental consent letters were distributed to the families of all children in the classes, and informed consent was required from all individual participants included in the study, as well as from their parents. Participation was anonymous and voluntary, and the respondents did not receive any payment or other forms of reimbursement for their participation. 


\section{Results}

\section{Correlations}

Table 1 presents the intercorrelations of student-teacher relationships, motivation to defend, and difficulties separately for boys and girls. Most correlations among the study variables were in the expected directions and similar for males and females. One exception may be noted; the correlation between difficulties and negative expectations were positive for boys $(r=.16)$ while there was no correlation for girls $(r=-.02)$. It may also be noted that age did not correlate with motivation to defend, but was negatively correlated with difficulties among both boys $(r=-.43)$ and girls $(r=-.13)$.

\section{Regression Analyses}

We conducted three-step hierarchical regression analyses separately for boys and girls to examine Hypotheses 1 and 2. There were three models each for boys and girls. In step 1 of the analyses, early adolescent difficulties were entered. In step 2, self-reported perceptions of their relationships with their main teachers were entered. Finally, in step 3, the two interaction terms between difficulties and student-teacher relationships were entered. As covariates that do not have any detectable effect should be excluded from regressions models (McCullagh and Nelder 1989), age was not entered in the models. As recommended by Aiken et al. (1991), all variables were grand-mean-centered to avoid problems with multicollinearity.

\section{Autonomous Motivation}

Hypotheses 1 was not supported, as shown in Table 2: namely, difficulties were not associated with neither boys' nor girls' autonomous motivation to defend. Hypothesis 2, that close student-teacher relationships would be associated with greater autonomous motivation to defend, was supported for boys $(\beta=.17, p=.027)$ and girls $(\beta=.24, p<.001)$. We also found that negative expectations were associated with greater autonomous motivation to defend in boys $(\beta=.24, p=.003)$ and girls $(\beta=.13, p=.044)$. The boys' main effects model explained $7 \%$ of the variance in their autonomous motivation to defend,

Table 1 Intercorrelations among the study variables of boys and girls

\begin{tabular}{lllllllll}
\hline & 1 & 2 & 3 & 4 & 5 & 6 & 7 \\
\hline 1 & Autonomous motivation & - & .11 & .12 & .09 & $.19^{* *}$ & .10 & .05 \\
2 & Introjected motivation & $-.19 * *$ & - & .12 & -.07 & $.23 * *$ & -.07 & -.09 \\
3 & Extrinsic motivation & -.04 & $.32 * *$ & - & $-.45^{* *}$ & $.42^{* *}$ & .05 & -.04 \\
4 & Close S-T-R & $.19 * *$ & $-.12^{*}$ & $-.41^{* *}$ & - & $-.34^{* *}$ & .01 & -.01 \\
5 & Negative expectations & .04 & $.29 * *$ & $.54 * *$ & $-.38^{* *}$ & - & $.16^{*}$ & $-.16^{*}$ \\
6 & Difficulties & .03 & $-.14^{*}$ & -.03 & .11 & -.02 & - & $-.43^{* *}$ \\
7 & Age & -.06 & -.04 & -.05 & .06 & .01 & $-.13^{* *}$ & - \\
\hline
\end{tabular}

$\mathrm{S}-\mathrm{T}-\mathrm{R}=$ student-teacher-relationships; correlations above the diagonal: Boys, $\mathrm{n}=184$; correlations below the diagonal: Girls, $\mathrm{n}=283$

$* p<.05 ; * * p<.01$ 
Table 2 Standardized regression coefficients and $t$ tests for motivation to defend for boys

\begin{tabular}{|c|c|c|c|c|c|c|}
\hline & \multicolumn{2}{|c|}{$\begin{array}{l}\text { Autonomous moti- } \\
\text { vation }\end{array}$} & \multicolumn{2}{|c|}{$\begin{array}{l}\text { Introjected motiva- } \\
\text { tion }\end{array}$} & \multicolumn{2}{|c|}{ Extrinsic motivation } \\
\hline & $B$ & $t$ test & $B$ & $t$ test & $\beta$ & $t$ test \\
\hline Difficulties & .10 & 1.34 & -.07 & -.90 & .05 & .62 \\
\hline Closeness & .17 & $2.22 *$ & .02 & -.24 & -.35 & $-5.24 * * *$ \\
\hline Negative expectations & .24 & $3.03 * *$ & .25 & $3.27 * * *$ & .31 & $4.50 * * *$ \\
\hline Difficulties $\times$ closeness & -.02 & -.23 & -.11 & -1.26 & -.05 & -.42 \\
\hline Difficulties $\times$ negative expectations & .09 & .85 & -.17 & -1.58 & -.20 & $-2.11^{*}$ \\
\hline
\end{tabular}

${ }^{*} p<.05 ; * * p<.01 ; * * * p<.001, \mathrm{n}=184$

$F(3,181)=4.22, p=.007$, whereas the girls' model explained $5 \%$ of the variance, $F(3$, $279)=5.10, p=.002$, which are considered small effects (Ferguson 2009). Examination of the two-way interactions indicated that there were no significant interaction effects for neither girls nor boys.

\section{Introjected Motivation}

In line with Hypothesis 1 , emotional and behavioral difficulties were associated with less introjected motivation to defend for girls $(\beta=-.15, p=.010)$, but not for boys (see Tables 2 and 3 ). In addition, negative expectations were associated with greater introjected motivation for both boys $(\beta=.25, p<.001)$ and girls $(\beta=.31, p<.001)$. The boys' main effects model explained $7 \%$ of the variance in introjected motivation to defend, $F(3,181)=4.14$, $p=.007$, while the girls' model explained $13 \%$ of the variance, $F(3,289)=13.89, p<.001$, which are considered small effects (Ferguson 2009). Examination of the two-way interactions indicated that there were no significant interaction effects for boys or girls.

\section{Extrinsic Motivation}

Contrary to Hypothesis 1, emotional and behavioral difficulties were not at all associated with boys' or girls' extrinsic motivation to defend. Thus, we did not get any support

Table 3 Standardized regression coefficients and $t$ tests for motivation to defend for girls

\begin{tabular}{|c|c|c|c|c|c|c|}
\hline & \multicolumn{2}{|c|}{$\begin{array}{l}\text { Autonomous motiva- } \\
\text { tion }\end{array}$} & \multicolumn{2}{|c|}{$\begin{array}{l}\text { Introjected motiva- } \\
\text { tion }\end{array}$} & \multicolumn{2}{|c|}{ Extrinsic motivation } \\
\hline & $B$ & $t$ test & $\beta$ & $t$ test & $\beta$ & $t$ test \\
\hline Difficulties & .03 & .49 & -.15 & $2.61 *$ & .01 & .22 \\
\hline Closeness & .24 & $3.83 * * *$ & -.02 & -.25 & -.24 & $-4.66^{* * * *}$ \\
\hline Negative expectations & .13 & $2.02 *$ & .31 & $5.23 * * *$ & .45 & $8.60 * * *$ \\
\hline Difficulties $\times$ closeness & .05 & .26 & .03 & .17 & .20 & 1.22 \\
\hline Difficulties $\times$ negative expectations & -.01 & -.12 & .04 & .59 & .18 & $2.97 * *$ \\
\hline
\end{tabular}

$* p<.05 ; * * p<.01 ; * * * p<.001, \mathrm{n}=282$ 
for Hypothesis 1. Concerning student-teacher relationships, the results were in support of Hypothesis 2: closeness was associated with less extrinsic motivation to defend in both boys $(\beta=-.35, p<.001)$ and girls $(\beta=-.24, p<.001)$. In addition, negative expectations were associated with greater extrinsic motivation to defend in both boys $(\beta=.31, p<.001)$ and girls $(\beta=.45, p<.001)$. The boys' main effects model explained $30 \%$ of the variance in their extrinsic motivation to defend, $F(5,179)=15.66, p<.001$, while the girls' model explained $37 \%$ of the variance, $F(5,287)=33.66, p<.001$, which are considered medium effects (Ferguson 2009).

When investigating the two-way interactions, we found that one of them was significant for boys. The pattern of this interaction is shown in Fig. 1, which was produced with an Excel worksheet that employed procedures by Dawson (2014) and Dawson and Richter (2006) to plot interaction effects. Boys with high levels of difficulties had lower extrinsic motivation to defend regardless of their degree of negative expectations of their teachers. In contrast, boys with low levels of difficulties had an even lower inclination to be extrinsically motivated to defend when negative expectations were low, whereas they displayed higher levels of extrinsic motivation when negative expectations were high $(\beta=-.20, p=.036)$. In fact, boys scored the highest on extrinsic motivation to defend when they displayed high levels of negative expectations and low levels of difficulties, whereas they scored lowest on extrinsic motivation to defend when they displayed low levels of both negative expectations and difficulties.

Concerning the two-way interaction for girls, the results showed that difficulties significantly interacted with negative expectations $(\beta=.18, p=.003)$. Both girls with high and low levels of difficulties were inclined to score lower on extrinsic motivation to defend when they experienced low negative expectations from their teachers and high on extrinsic motivation when they experienced high negative expectations (see Fig. 2).

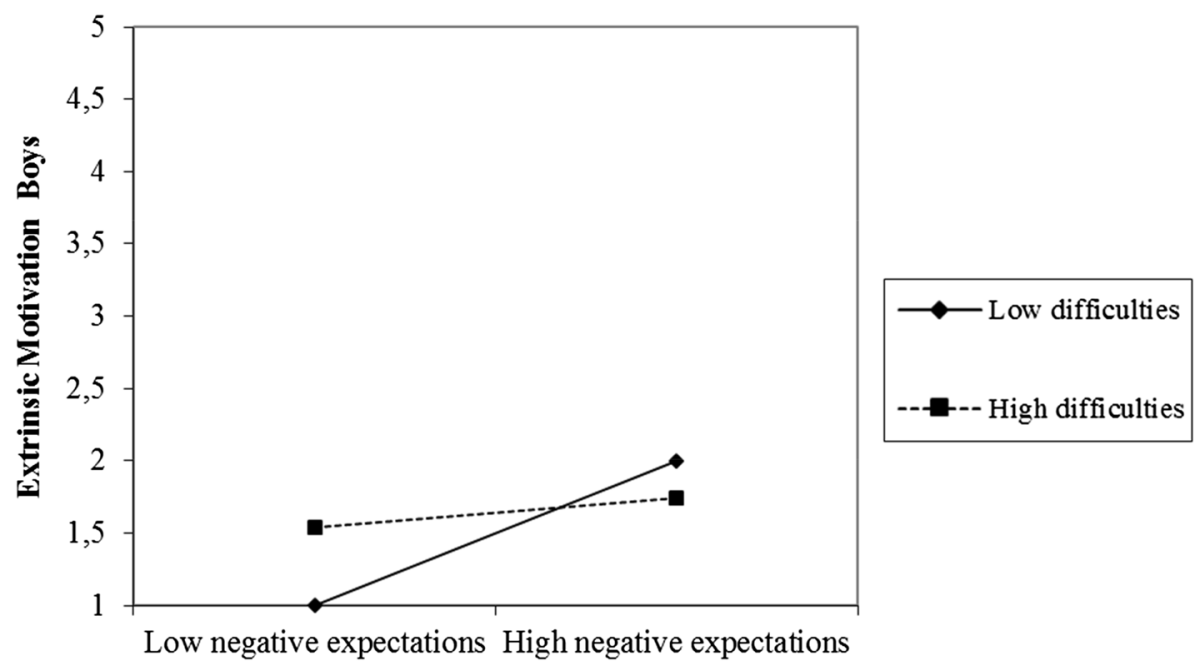

Fig. 1 Interaction effect of students' negative expectations and emotional and behavioral difficulties on extrinsic motivation in boys 


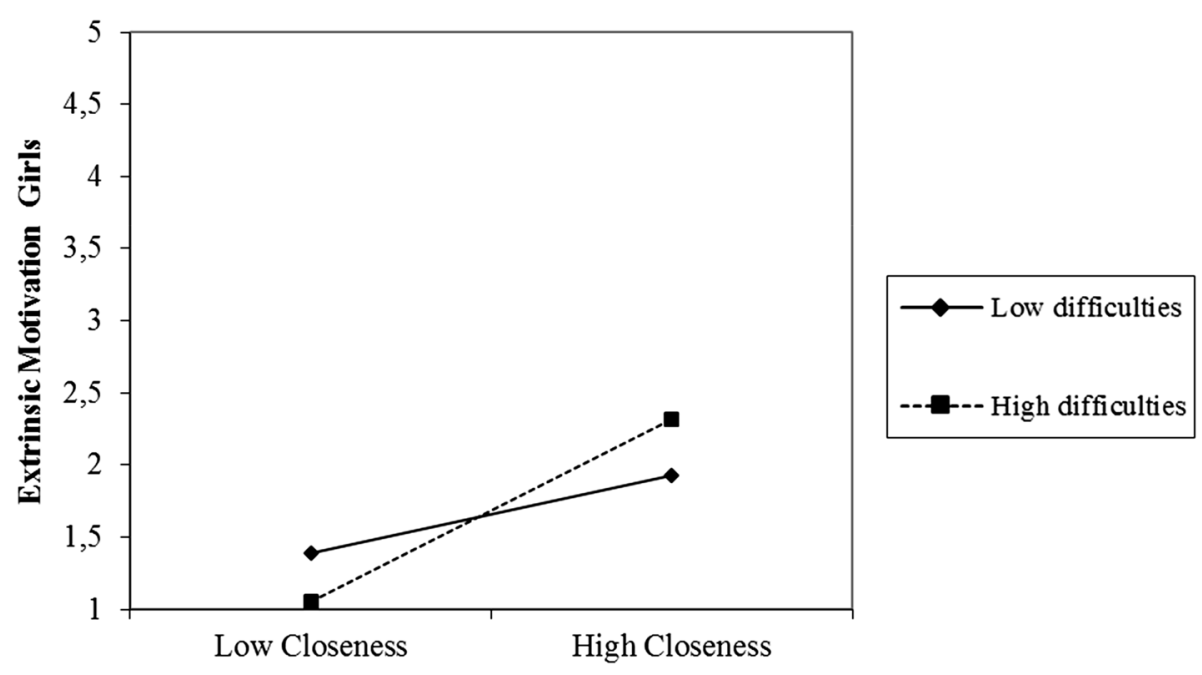

Fig. 2 Interaction effect of students' close student-teacher relationship and emotional and behavioral difficulties on extrinsic motivation in girls

\section{Discussion}

The present study aimed to provide evidence that young adolescents' emotional and behavioral difficulties, and student-teacher relationships are associated with motivation to defend school bully victims. We focused on these aspects of emotional, behavioral, and relational development as critical foundations to consider in fortifying students' autonomous motivation to defend victims. In addition, we investigated age and possible interaction effects.

\section{Emotional and Behavioral Difficulties}

Contrary to our expectations (Hypothesis 1), the current findings suggest that boys and girls can be autonomously and extrinsically motivated to defend victims of bullying in various degrees independently of emotional and behavioral difficulties. We would have expected that low degrees of emotional and behavioral difficulties would be associated with autonomous motivation to defend, as this type of motivation is related to being aware and experiencing insight, choice, and volition (Ryan and Deci 2017). We had expected this to be easier for students with higher well-being. On the other hand, Jenkin and colleagues' (2017) study showed that emotional and behavioral difficulties might not be linked to defending in a way that we might expect. A possible explanation could be that adolescent's moral willingness to help victims in school bullying situations may be influenced by other individual and contextual factors (e.g., compassion, empathy, proneness to be angry toward bullies, social status, and peer norms) rather than poor self-regulation skills, psychological and psychosomatic problems, hyperactivity/attention problems, conduct problems, and peer relationship problems. This could be compared with research showing that bullies do not differ from peers in terms of deficits in social cognition but in higher levels of moral disengagement (Gini 2006), and display advanced moral competence to judge, but lack 
moral compassion (Gini et al. 2011). However, girls with difficulties were less likely to be introjectedly motivated to defend, which supports Hypothesis 1 partially. It might be possible that adolescent girls with low degrees of emotional and behavioral difficulties to some extent feel prideful and morally righteous when they think of helping a victim, which may explain the association with introjected motivation to defend.

Also note that although autonomous motivation to defend has been linked to actual defending (Jungert et al. 2016), adolescents who scored high on autonomous motivation might still be less inclined to actually defend victims due to various other reasons, such as low defender self-efficacy (Barchia and Bussey 2011; Pöyhönen et al. 2012; Thornberg and Jungert 2013), being less inclined to be angry when witnessing bullying (Pozzoli et al. 2017), low empathy (Barchia and Bussey 2011; Batanova et al. 2014), poor student-teacher relationship quality (Jungert et al. 2016), and high moral disengagement proneness (Gini 2006; Thornberg and Jungert 2013; Thornberg et al. 2017). Our study, however, was the first to examine the relationships between emotional and behavioral difficulties and the three forms of motivation to defend bullying victims, so more research is needed to determine if this holds up in other countries, age groups, and sociodemographic groups.

\section{Student-Teacher Relationships}

Our findings revealed that close student-teacher relationships were associated with greater autonomous and less extrinsic motivation to defend in both girls and boys. This supports our expectations for girls (Hypothesis 2) and the findings of a previous study (Jungert et al. 2016). Altogether, this can be compared with research showing the positive link between close student-teacher relationships and actual defending in school bullying (Jungert et al. 2016; Thornberg et al. 2017). Even if the explanation of variance in autonomous motivation was small, it is plausible that close, warm and supportive student-teacher relationships are not only a protective factor in relation to bullying perpetration (Richard et al. 2012) and victimization (Thornberg et al. 2017) but also a healthy factor that seems to promote autonomous motivation to defend and actual defender behavior in school bullying. In accordance with SDT (Deci and Ryan 2000), close student-teacher relationships may be connected with the satisfaction of needs, which is required for autonomous motivation. Overall, the coefficients for student-teacher relationships indicate that they are of important relevance for motivation to defend victims.

Additionally, negative expectations did not discriminate between autonomous, introjected and extrinsic motivation to defend, but were positively associated with all of them. Negative expectations have broadly been accepted as a negative relational factor (Koomen and Jellesma 2015). Students who feel insecure might seek their teacher's attention, feeling that their teacher would listen more and spend more time with them, while also experiencing strong feelings of guilt or shame, which are important forces governing introjected motivation (Deci and Ryan 2000). Similarly, its positive link with extrinsic motivation to defend suggests that students who have a stronger desire for more positive attention from their teachers might also be more controlled by external contingencies when it comes to defending victims or not. However, the fact that it was associated with greater autonomous motivation to defend as well, indicates that negative expectations might be a more ambiguous concept than Koomen and Jellesma (2015) assume. Adolescents who are more occupied with wanting to have a better relationship with their teachers might, in general, be motivated to 
be involved in good social relationships with others and to be a good person. Future research is needed to examine the possible underlying reasons behind this, and discriminate between different states of negative expectations in student-teacher relationships.

\section{Interaction Effects}

The current findings suggest that boys who have a stronger desire for more positive attention from their teachers (i.e., negative expectations) might be more controlled by external contingencies (i.e., extrinsic motivation) in the case of defending victims if they scored low in behavioral and emotional difficulties. This was not the case for boys high in difficulties as they had similar levels of extrinsic motivation regardless of their negative expectations. In contrast, girls high in difficulties had a slightly higher extrinsic motivation when they had high negative expectations. Future research should examine how gender norms might interact with emotional and behavioral difficulties to better understand why negative expectations seem to play different roles for boys and girls in the link between difficulties and extrinsic motivation.

\section{Limitations}

Despite the many strengths of this study, some limitations should be noted. As we adopted a cross-sectional design, we were not able to pinpoint the direction of the effects. For example, it is not clear whether the warm, supportive, and close student-teacher relationship qualities are predictors of autonomous motivation to defend, or if this motivation fits into a mindset that predicts closeness in student-teacher relationships. It is also possible that the relations noted in the present study are reciprocal. Another limitation is that all data were collected with self-report measures, which are vulnerable to social desirability and shared method variance. Finally, a note of caution needs to be sounded regarding the generalization of the findings. The qualities of the sample-in terms of non-randomization, country, age, and participation rate-suggest that the study is vulnerable to selection bias; accordingly, the sample may or may not be similar to the population of students with whom the readers primarily work with or are interested in.

\section{Future Directions}

Future studies should have a tighter focus on different types of bullying (e.g. physical and relational) and bystanders' motivation to intervene when witnessing school bullying. In addition, future research should include peer ratings to add to the measurement of the participants' difficulties as well as to better capture different aspects of functioning (Lahey and Willcutt 2010). Furthermore, teacher ratings of their students' emotional and behavioral difficulties should be obtained in future studies. In particular, future research should examine whether emotional and behavioral difficulties interact with other variables that have been linked with defending to better explain the variability of autonomous, introjected, and extrinsic motivation to defend. Perhaps future research could also examine whether there are differences in student-teacher relationships and in emotional and behavioral difficulties between bystanders who are motivated to defend friends versus other peers. Finally, 
future studies could include measures of whether student bystanders intervene and how they intervene.

\section{Implications}

Previous research has demonstrated that bystanders matter as the between-classroom variability in bullying can be explained in part by how the classmates usually respond as bystanders. The less they take the bullies' side and the more they defend the victims, the less often bullying is likely to take place (Kärnä et al. 2011; Nocentini et al. 2013; Salmivalli et al. 2011). In addition, autonomous motivation to defend has been associated with greater defending (Jungert et al. 2016). Increasing students' autonomous motivation to defend should therefore be addressed in bullying prevention and knowing more about how teachers can influence students' autonomous motivation to defend is crucial. In addition to prior research showing that close, warm and supportive student-teacher relationships are associated with less bullying (Gregory et al. 2010; Richard et al. 2012) and greater defending (Jungert et al. 2016), the current findings demonstrate their link to greater autonomous motivation and less extrinsic motivation to defend. Whereas the former type of motivation is related to agency, persistence and actual behavior (Deci and Ryan 2000; Ryan and Deci 2017), the latter is more vulnerable to peer pressure and other forms of social influence that might inhibit actual defending. Thus, the present findings further support the importance of establishing and maintaining warm and caring student-teacher relationships as a part of bullying prevention in schools. Teachers need to consciously build warm and caring relationships with their students, as this is associated with students' autonomous motivation to defend and actual defending in bullying as well as with less bullying at school. Notably, negative expectations were positively associated with all three forms of motivation to defend, although the link was strongest with extrinsic motivation, which in turn has been associated with pro-bullying and passive bystander behavior (Jungert et al. 2016). Thus, positive, healthy and close rather than insecure, dependent and anxious relationships between teachers and students should be developed to facilitate defending, and to counteract bullying in schools. At the class level, Thornberg et al. (2017) found that positive (caring, warm, and supportive) student-teacher relationships were associated with positive peer relationships, which in turn were associated with a lower weekly prevalence of victimized classmates. Positive and caring student-teacher relationships might contribute to the development of prosocial values, motivation and behavioral patterns (cf., Luckner and Pianta 2011), including autonomous motivation to stand up for victims and higher likelihood to defend, which in turn might work together as protective factors to bullying. In sum, our findings suggest that bullying prevention programs need to increase students' autonomous motivation to defend victims by supporting teachers in establishing and maintaining warm and close relationships with their students.

Acknowledgements Open access funding provided by Lund University.

\section{Compliance with Ethical Standards}

Conflict of interest The authors declare that they have no conflict of interest.

Human Participants and/or Animals Research involved human subjects, with all procedures approved by the Department of Psychology at the university.

Informed Consent Informed parental consent and child assent were obtained for all study participants. 
Open Access This article is distributed under the terms of the Creative Commons Attribution 4.0 International License (http://creativecommons.org/licenses/by/4.0/), which permits unrestricted use, distribution, and reproduction in any medium, provided you give appropriate credit to the original author(s) and the source, provide a link to the Creative Commons license, and indicate if changes were made.

\section{References}

Aiken, L. S., West, S. G., \& Reno, R. R. (1991). Multiple regression: Testing and interpreting interactions. Thousand Oaks: Sage.

Andrade, B. F., \& Tannock, R. (2014). Sustained impact of inattention and hyperactivity-impulsivity on peer problems: Mediating roles of prosocial skills and conduct problems in a community sample of children. Child Psychiatry and Human Development, 45(3), 318-328.

Aron, A., Coups, E., \& Aron, E. N. (2013). Statistics for the behavioral and social sciences: Pearson new international edition: A brief course. London: Pearson Higher Ed.

Barchia, K., \& Bussey, K. (2011). Individual and collective social cognitive influences on peer aggression: Exploring the contribution of aggression efficacy, moral disengagement, and collective efficacy. Aggressive Behavior, 37(2), 107-120. https://doi.org/10.1002/ab.20375.

Barkley, R. A. (2014). Attention-deficit hyperactivity disorder: A handbook for diagnosis and treatment. New York: Guilford Publications.

Batanova, M., Espelage, D. L., \& Rao, M. A. (2014). Early adolescents' willingness to intervene: What roles do attributions, affect, coping, and self-reported victimization play? Journal of School Psychology, 52(3), 279-293.

Baumeister, R. F., \& Leary, M. R. (1995). The need to belong: Desire for interpersonal attachments as a fundamental human motivation. Psychological Bulletin, 117(3), 497.

Bentler, P. M. (1995). EQS structural equations program manual. Temple City: Multivariate Software.

Bloomquist, M. L., August, G. J., Cohen, C., Doyle, A., \& Everhart, K. (1997). Social problem solving in hyperactive-aggressive children: How and what they think in conditions of automatic and controlled processing. Journal of Clinical Child Psychology, 26(2), 172-180.

Chester, K. L., Callaghan, M., Cosma, A., Donnelly, P., Craig, W., Walsh, S., et al. (2015). Crossnational time trends in bullying victimization in 33 countries among children aged 11,13 and 15 from 2002 to 2010. The European Journal of Public Health, 25(suppl_2), 61-64.

Crick, N. R., Casas, J. F., \& Nelson, D. A. (2002). Toward a more comprehensive understanding of peer maltreatment: Studies of relational victimization. Current Directions in Psychological Science, 11(3), 98-101.

Dawson, J. F. (2014). Moderation in management research: What, why, when, and how. Journal of Business and Psychology, 29(1), 1-19.

Dawson, J. F., \& Richter, A. W. (2006). Probing three-way interactions in moderated multiple regression: Development and application of a slope difference test. Journal of Applied Psychology, 91(4), 917-926.

Deci, E. L., \& Ryan, R. M. (2000). The" what" and" why" of goal pursuits: Human needs and the selfdetermination of behavior. Psychological Inquiry, 11(4), 227-268.

Espelage, D., Green, H., \& Polanin, J. (2012). Willingness to intervene in bullying episodes among middle school students: Individual and peer-group influences. The Journal of Early Adolescence, 32(6), $776-801$.

Ferguson, C. J. (2009). An effect size primer: A guide for clinicians and researchers. Professional Psychology: Research and Practice, 40(5), 532.

Gaub, M., \& Carlson, C. L. (1997). Gender differences in ADHD: A meta-analysis and critical review. Journal of the American Academy of Child and Adolescent Psychiatry, 36(8), 1036-1045.

Gini, G. (2006). Social cognition and moral cognition in bullying: What's wrong? Aggressive Behavior, 32(6), 528-539.

Gini, G. (2008). Associations between bullying behaviour, psychosomatic complaints, emotional and behavioural problems. Journal of Paediatrics and Child Health, 44(9), 492-497. https://doi.org/10. 1111/j.1440-1754.2007.01155.x.

Gini, G., Pozzoli, T., \& Hauser, M. (2011). Bullies have enhanced moral competence to judge relative to victims, but lack moral compassion. Personality and Individual Differences, 50(5), 603-608.

Goodman, R. (1997). The strengths and difficulties questionnaire: A research note. Journal of Child Psychology and Psychiatry, 38(5), 581-586. 
Goodman, R., Meltzer, H., \& Bailey, V. (1998). The strengths and difficulties questionnaire: A pilot study on the validity of the self-report version. European Child \& Adolescent Psychiatry, 7(3), 125-130.

Gregory, A., Cornell, D., Fan, X., Sheras, P., Shih, T. H., \& Huang, F. (2010). Authoritative school discipline: High school practices associated with lower bullying and victimization. Journal of Educational Psychology, 102(2), 483-496.

Hampel, P., \& Petermann, F. (2006). Perceived stress, coping, and adjustment in adolescents. Journal of Adolescent Health, 38(4), 409-415.

Hankin, B. L., Mermelstein, R., \& Roesch, L. (2007). Sex differences in adolescent depression: Stress exposure and reactivity models. Child Development, 78(1), 279-295.

Hardy, S. A., Dollahite, D. C., Johnson, N., \& Christensen, J. B. (2015). Adolescent motivations to engage in pro-social behaviors and abstain from health-risk behaviors: A self-determination theory approach. Journal of Personality, 83(5), 479-490. https://doi.org/10.1111/jopy.12123.

Hoza, B. (2007). Peer functioning in children with ADHD. Journal of Pediatric Psychology, 32(6), 655-663.

Jenkins, L. N., Demaray, M. K., \& Tennant, J. (2017). Social, emotional, and cognitive factors associated with bullying. School Psychology Review, 46(1), 42-64.

Jungert, T., Piroddi, B., \& Thornberg, R. (2016). Early adolescents' motivations to defend victims in school bullying and their perceptions of student-teacher relationships: A self-determination theory approach. Journal of Adolescence, 53, 75-90.

Kärnä, A., Voeten, M., Little, T. D., Poskiparta, E., Kaljonen, A., \& Salmivalli, C. (2011). A large-scale evaluation of the KiVa antibullying program: Grades 4-6. Child Development, 82(1), 311-330.

Kasser, T., Ryan, R. M., Zax, M., \& Sameroff, A. J. (1995). The relations of maternal and social environments to late adolescents' materialistic and prosocial values. Developmental Psychology, 31(6), 907.

Koomen, H. M., \& Jellesma, F. C. (2015). Can closeness, conflict, and dependency be used to characterize students' perceptions of the affective relationship with their teacher? Testing a new child measure in middle childhood. British Journal of Educational Psychology, 85(4), 479-497.

Lahey, B. B., \& Willcutt, E. G. (2010). Predictive validity of a continuous alternative to nominal subtypes of attention-deficit/hyperactivity disorder for DSM-V. Journal of Clinical Child and Adolescent Psychology, 39(6), 761-775.

Longobardi, C., Prino, L. E., Marengo, D., \& Settanni, M. (2016). Student-teacher relationships as a protective factor for school adjustment during the transition from middle to high school. Frontiers in Psychology, 7, 1988.

Luckner, A. E., \& Pianta, R. C. (2011). Teacher-student interactions in fifth grade classrooms: Relations with children's peer behavior. Journal of Applied Developmental Psychology, 32(5), 257-266.

Malmberg, M., Rydell, A.-M., \& Smedje, H. (2003). Validity of the Swedish version of the strengths and difficulties questionnaire (SDQ-Swe). Nordic Journal of Psychiatry, 57(5), 357-363. https://doi. org/10.1080/08039480310002697.

McCullagh, P., \& Nelder, J. A. (1989). Generalized linear models (Vol. 37). Boca Raton: CRC Press.

McGrath, K. F., \& Van Bergen, P. (2015). Who, when, why and to what end? Students at risk of negative student-teacher relationships and their outcomes. Educational Research Review, 14, 1-17.

Meeus, W. (2016). Adolescent psychosocial development: A review of longitudinal models and research. Developmental Psychology, 52(12), 1969-1993. https://doi.org/10.1037/dev0000243.

Myers, T. A. (2011). Goodbye, listwise deletion: Presenting hot deck imputation as an easy and effective tool for handling missing data. Communication Methods and Measures, 5(4), 297-310.

Nocentini, A., Menesini, E., \& Salmivalli, C. (2013). Level and change of bullying behavior during high school: A multilevel growth curve analysis. Journal of Adolescence, 36(3), 495-505.

Oh, I., \& Hazler, R. J. (2009). Contributions of personal and situational factors to bystanders' reactions to school bullying. School Psychology International, 30(3), 291-310.

Pöyhönen, V., Juvonen, J., \& Salmivalli, C. (2012). Standing up for the victim, siding with the bully or standing by? Bystander responses in bullying situations. Social Development, 21(4), 722-741. https:// doi.org/10.1111/j.1467-9507.2012.00662.x.

Pozzoli, T., Gini, G., \& Thornberg, R. (2017). Getting angry matters: Going beyond perspective taking and empathic concern to understand bystanders' behavior in bullying. Journal of Adolescence, 61, 87-95.

Prinstein, M. J., Cheah, C. S., \& Guyer, A. E. (2005). Peer victimization, cue interpretation, and internalizing symptoms: Preliminary concurrent and longitudinal findings for children and adolescents. Journal of Clinical Child and Adolescent Psychology, 34(1), 11-24.

Richard, J. F., Schneider, B. H., \& Mallet, P. (2012). Revisiting the whole-school approach to bullying: Really looking at the whole school. School Psychology International, 33(3), 263-284.

Roth, P. L., Switzer, F. S., III, \& Switzer, D. M. (1999). Missing data in multiple item scales: A Monte Carlo analysis of missing data techniques. Organizational Research Methods, 2(3), 211-232. 
Ryan, A. M., \& Patrick, H. (2001). The classroom social environment and changes in adolescents' motivation and engagement during middle school. American Educational Research Journal, 38(2), 437-460.

Ryan, R. M., \& Deci, E. L. (2017). Self-determination theory. New York, NY: The Guilford.

Salmivalli, C. (2010). Bullying and the peer group: A review. Aggression and Violent Behavior, 15(2), $112-120$.

Salmivalli, C., Voeten, M., \& Poskiparta, E. (2011). Bystanders matter: Associations between reinforcing, defending, and the frequency of bullying behavior in classrooms. Journal of Clinical Child and Adolescent Psychology, 40(5), 668-676.

Thornberg, R., \& Jungert, T. (2013). Bystander behavior in bullying situations: Basic moral sensitivity, moral disengagement and defender self-efficacy. Journal of Adolescence, 36(3), 475-483.

Thornberg, R., Wänström, L., Hong, J. S., \& Espelage, D. L. (2017a). Classroom relationship qualities and social-cognitive correlates of defending and passive bystanding in school bullying in Sweden: A multilevel analysis. Journal of School Psychology, 63, 49-62.

Thornberg, R., Wänström, L., \& Pozzoli, T. (2017b). Peer victimisation and its relation to class relational climate and class moral disengagement among school children. Educational Psychology, 37(5), 524-536.

Thornberg, R., Wänström, L., Pozzoli, T., \& Gini, G. (2017c). Victim prevalence in bullying and its association with teacher-student and student-student relationships and class moral disengagement: a classlevel path analysis. Research Papers in Education, 33, 1-16.

Trach, J., Hymel, S., Waterhouse, T., \& Neale, K. (2010). Bystander responses to school bullying: A crosssectional investigation of grade and sex differences. Canadian Journal of School Psychology, 25(1), $114-130$.

Waters, S. K., Cross, D. S., \& Runions, K. (2009). Social and ecological structures supporting adolescent connectedness to school: A theoretical model. Journal of School Health, 79(11), 516-524.

Weinstein, N., \& Ryan, R. M. (2010). When helping helps: Autonomous motivation for prosocial behavior and its influence on well-being for the helper and recipient. Journal of Personality and Social Psychology, 98(2), 222.

Wentzel, K. R. (2017). Peer relationships, motivation, and academic performance at school. In A. J. Elliot, C. S. Dweck, D. S. Yeager, A. J. Elliot, C. S. Dweck, \& D. S. Yeager (Eds.), Handbook of competence and motivation: Theory and application (pp. 586-603). New York, NY: Guilford Press.

Publisher's Note Springer Nature remains neutral with regard to jurisdictional claims in published maps and institutional affiliations. 